\title{
The Role of Oxygen in the Degradation of Methylammonium Lead Trihalide Perovskite Photoactive Layers
}

Nicholas Aristidou, Irene Sanchez-Molina, Thana Chotchuangchutchaval, Michael Brown, Luis Martinez, Thomas Rath and Saif A. Haque*

Department of Chemistry, Imperial College London, South Kensington Campus, London SW7 2AZ, United Kingdom.

Corresponding Author email: s.a.haque@imperial.ac.uk

In this paper we report on the influence of light and oxygen on the stability of $\mathrm{CH}_{3} \mathrm{NH}_{3} \mathrm{PbI}_{3}$ perovskite based photoactive layers. When exposed to both light and dry air the mp- $\mathrm{Al}_{2} \mathrm{O}_{3} / \mathrm{CH}_{3} \mathrm{NH}_{3} \mathrm{PbI}_{3}$ photoactive layers decompose yielding methylamine, $\mathrm{PbI}_{2}$ and $\mathrm{I}_{2}$ as products. We show that this degradation is initiated by the reaction of superoxide $\left(\mathrm{O}_{2}^{-}\right)$with the methylammonium moiety of the perovskite absorber. Fluorescent molecular probe studies indicate that the $\mathrm{O}_{2}^{-}$species is generated by the reaction of photoexcited electrons in the perovskite and molecular oxygen. We show that the yield of $\mathrm{O}_{2}^{-}$generation is significantly reduced when the $m p-\mathrm{Al}_{2} \mathrm{O}_{3}$ film is replaced with an $\mathrm{mp}-\mathrm{TiO}_{2}$ electron extraction and transport layer. The present findings suggest that replacing the methylammonium component in $\mathrm{CH}_{3} \mathrm{NH}_{3} \mathrm{PbI}_{3}$ to a species without acid protons could improve tolerance to oxygen and enhance stability.

Over the last few years, organic lead halide perovskites have aroused enormous interest with respect to their application in low-cost, solution-processable photovoltaics. A wide 
range of device architectures employing such perovskite absorbers have been reported so far, with efficiencies approaching $20 \% \cdot{ }^{[1-4]}$ In spite of this tremendous progress, a number of key issues must be overcome before wide-spread commercialization is possible, mainly, those associated with toxicity of lead and long-term material stability. Regarding the latter, UV irradiation, ${ }^{[5]}$ and water, are well known to affect the stability of methylammonium lead triiodide $\left(\mathrm{CH}_{3} \mathrm{NH}_{3} \mathrm{PbI}_{3}, \mathrm{MAPbI}_{3}, \mathrm{MAPI}\right) .^{[1,6,7]}$ For example, humidity can degrade the $\mathrm{CH}_{3} \mathrm{NH}_{3} \mathrm{PbI}_{3}$ absorber and reduce photovoltaic device performance by about $80 \%$ in $24 \mathrm{~h} \cdot{ }^{[6]}$ Recently, a few mechanistic studies on the action of water on $\mathrm{CH}_{3} \mathrm{NH}_{3} \mathrm{PbI}_{3}$ have been reported, identifying lead (II) iodide as one of the final products, although different degradation pathways were proposed ${ }^{[8,9]}$ Moreover, we have recently reported that decomposition of $\mathrm{CH}_{3} \mathrm{NH}_{3} \mathrm{PbI}_{3}$ can also be triggered by the combination of molecular oxygen and light. ${ }^{[10]}$ More specifically, in our previous work we employed transient absorption spectroscopy to monitor the yield of long-lived charge separation in mesoporous $\mathrm{TiO}_{2} / \mathrm{CH}_{3} \mathrm{NH}_{3} \mathrm{PbI}_{3} /$ spiro-OMeTAD and $\mathrm{Al}_{2} \mathrm{O}_{3} / \mathrm{CH}_{3} \mathrm{NH}_{3} \mathrm{PbI}_{3} /$ spiro-OMeTAD photoactive layers before and after exposure to light and oxygen. After the ageing process, the mesoporous $\mathrm{Al}_{2} \mathrm{O}_{3}$ based samples showed a rapid and substantial drop in the yield of long-lived charge separation. We attributed this drop in yield to degradation of the $\mathrm{CH}_{3} \mathrm{NH}_{3} \mathrm{PbI}_{3}$ absorber resulting from a reaction between oxygen and the photoexcited electrons in $\mathrm{CH}_{3} \mathrm{NH}_{3} \mathrm{PbI}_{3}$. Moreover, this degradation pathway was apparently hindered in the mesoporous $\mathrm{TiO}_{2}$ based samples; here electron injection from the photoexcited state of $\mathrm{CH}_{3} \mathrm{NH}_{3} \mathrm{PbI}_{3}$ precludes this parasitic decomposition reaction. In this paper, we build on previous work and report on the mechanism of this photodegradation reaction. Specifically, we show that the combined action of light and molecular oxygen on $\mathrm{CH}_{3} \mathrm{NH}_{3} \mathrm{PbI}_{3}$ photoactive layers results in the decomposition of the perovskite leading to the formation of $\mathrm{PbI}_{2}, \mathrm{I}_{2}$ and 
methylamine. Importantly, we show that this photodegradation reaction is triggered by the action of a reactive oxygen species (superoxide; $\mathrm{O}_{2}^{-}$) on the organic (i.e. methylammonium) component of the $\mathrm{CH}_{3} \mathrm{NH}_{3} \mathrm{PbI}_{3}$ perovskite absorber. The present findings indicate that the identification of alternative cations to methylammonium $\left(\mathrm{CH}_{3} \mathrm{NH}_{3}{ }^{+}\right)$may be of crucial importance to the design of environmentally stable organometal trihalide perovskite photovoltaic devices.

In order to investigate whether superoxide generation contributes to the degradation of MAPI solar cells and leads to their reduced photochemical stability under illumination in a moisture-free atmosphere, a molecular fluorescent probe, hydroethidine (HE) was employed. This compound is known to show a characteristic increase in emission at $610 \mathrm{~nm}$ upon exposure to the superoxide radical anion. ${ }^{[1]} \mathrm{CH}_{3} \mathrm{NH}_{3} \mathrm{PbI}_{3}$ films were fabricated onto two glass substrates coated either with mp- $\mathrm{TiO}_{2}$ or mp- $\mathrm{Al}_{2} \mathrm{O}_{3}$. The resulting mp- $\mathrm{TiO}_{2} / \mathrm{CH}_{3} \mathrm{NH}_{3} \mathrm{PbI}_{3}$ and $\mathrm{mp}-\mathrm{Al}_{2} \mathrm{O}_{3} / \mathrm{CH}_{3} \mathrm{NH}_{3} \mathrm{PbI}_{3}$ films were then immersed into a $0.317 \mu \mathrm{M}$ solution of the HE probe in dry toluene. The photo-degradation conditions consisted of ageing the samples under continuous illumination from a tungsten lamp $\left(\sim 1.5 \mathrm{mWcm}^{-1}\right)$ and dry air flow (21\% oxygen content). In the current experiment, the fluorescence emission of the HE probe was monitored at regular time intervals over the course of 1 hour with the mp- $\mathrm{TiO}_{2} / \mathrm{CH}_{3} \mathrm{NH}_{3} \mathrm{PbI}_{3}$ and mp$\mathrm{Al}_{2} \mathrm{O}_{3} / \mathrm{CH}_{3} \mathrm{NH}_{3} \mathrm{PbI}_{3}$ films exposed to light and dry air. Figure 1a shows the emission characteristics of HE (fluorescence intensity versus wavelength) as a function of ageing time for both mp- $\mathrm{TiO}_{2} / \mathrm{CH}_{3} \mathrm{NH}_{3} \mathrm{PbI}_{3}$ and $\mathrm{mp}-\mathrm{Al}_{2} \mathrm{O}_{3} / \mathrm{CH}_{3} \mathrm{NH}_{3} \mathrm{PbI}_{3}$. The rate of increase in emission $\left(\left[\mathrm{I}_{\mathrm{F}}(\mathrm{t}) /\left[\mathrm{I}_{\mathrm{F}}\left(\mathrm{t}_{0}\right)\right]\right.\right.$ at $610 \mathrm{~nm}$ versus ageing time), and therefore superoxide generation is shown in Figure 1b. Control measurements performed in the absence of light (green curve, Figure 1b) showed no increase in HE emission at $610 \mathrm{~nm}$, indicating 
that the process is photo-induced. Similarly, when the dry air stream was replaced with nitrogen and illumination introduced there was no detectable increase in fluorescence intensity (red curve, Figure $1 b$ ). In contrast, when the mp- $\mathrm{TiO}_{2} / \mathrm{CH}_{3} \mathrm{NH}_{3} \mathrm{PbI}_{3}$ and $\mathrm{mp}-$ $\mathrm{Al}_{2} \mathrm{O}_{3} / \mathrm{CH}_{3} \mathrm{NH}_{3} \mathrm{PbI}_{3}$ samples were exposed to both dry air and light, the expected increase of fluorescence of the probe was observed, which is consistent with the presence of superoxide in the solution. However, it is apparent from the data presented in Figure $1 \mathrm{~b}$ that a higher yield of superoxide generation is observed in the mp$\mathrm{Al}_{2} \mathrm{O}_{3} / \mathrm{CH}_{3} \mathrm{NH}_{3} \mathrm{PbI}_{3}$ film as compared to the analogous mp- $\mathrm{TiO}_{2} / \mathrm{CH}_{3} \mathrm{NH}_{3} \mathrm{PbI}_{3}$ sample. The next question that arises relates to why the mp- $\mathrm{Al}_{2} \mathrm{O}_{3} / \mathrm{CH}_{3} \mathrm{NH}_{3} \mathrm{PbI}_{3}$ film exhibits a greater yield of superoxide generation than the mp- $\mathrm{TiO}_{2} / \mathrm{CH}_{3} \mathrm{NH}_{3} \mathrm{PbI}_{3}$ sample. A key difference between using a mesoporous $\mathrm{TiO}_{2}$ and $\mathrm{Al}_{2} \mathrm{O}_{3}$ films is that the $\mathrm{TiO}_{2}$ film can accept an electron from the photoexcited perovskite, due to a favorable energy offset at the heterojunction, ${ }^{[12]}$ as shown in Figure 2. This, in turn, would reduce the number of photoexcited electrons in the perovskite available for electron transfer to oxygen, thereby reducing the yield of superoxide generation, which is consistent with the data presented in Figure 1. We hypothesize that superoxide generation in the mp$\mathrm{TiO}_{2} / \mathrm{CH}_{3} \mathrm{NH}_{3} \mathrm{PbI}_{3}$ film is most likely due to the presence of a $\mathrm{CH}_{3} \mathrm{NH}_{3} \mathrm{PbI}_{3}$ overlayer as revealed by SEM studies. Support for this assertion comes from cross-sectional scanning electron microscopy studies which revealed the presence of an approximately $50 \mathrm{~nm}$ thick overlayer of perovskite in both mp- $\mathrm{Al}_{2} \mathrm{O}_{3} / \mathrm{CH}_{3} \mathrm{NH}_{3} \mathrm{PbI}_{3}$ and mp$\mathrm{TiO}_{2} / \mathrm{CH}_{3} \mathrm{NH}_{3} \mathrm{PbI}_{3}$ films (see supporting information, Figure $\mathrm{S} 1$ ). As such, the reduced rate of production of superoxide in the $\mathrm{TiO}_{2}$ based samples compared to that of the $\mathrm{Al}_{2} \mathrm{O}_{3}$ based films could thus arise as a consequence of the electron transfer process from $\mathrm{CH}_{3} \mathrm{NH}_{3} \mathrm{PbI}_{3}$ to the $\mathrm{TiO}_{2}$ layer being in direct competition with the reaction of the photo-generated electrons with oxygen. Furthermore, it is pertinent to note that our 
observation of increased superoxide production in $\mathrm{Al}_{2} \mathrm{O}_{3}$ samples is in good agreement with our previous work showing a rapid and profound degradation in the yield of photoinduced charge separation in mp- $\mathrm{Al}_{2} \mathrm{O}_{3} / \mathrm{CH}_{3} \mathrm{NH}_{3} \mathrm{PbI} /$ spiro-OMeTAD films upon exposure to light and dry air. ${ }^{[10]}$

We now consider the compositional changes in the $\mathrm{CH}_{3} \mathrm{NH}_{3} \mathrm{PbI}_{3}$ perovskite film resulting from the ageing process. To elucidate the products of the degradation that occurs as a result of the combination of light and dry air, we immersed the substrates in dry toluene under a constant flow of dry oxygen and illumination, thus excluding moisture. Similar to the $\mathrm{HE}$ probe experiments, $\mathrm{mp}-\mathrm{Al}_{2} \mathrm{O}_{3}$ based films were immersed in dry toluene and then a constant flow of dry oxygen and illumination were used to create the controlled degradation conditions. It was noted that after 72 hours exposure to both light and oxygen the $\mathrm{CH}_{3} \mathrm{NH}_{3} \mathrm{PbI}_{3}$ perovskite films changed colour from dark brown to yellow and the toluene solution turned light pink, most likely due to the formation of iodine. UV-Vis spectroscopy was used to monitor the evolution of iodine in the solution (Figure 3a). The change in the absorption spectra is consistent with the production of iodine, as the detected absorption spectrum resembles the absorption of iodine. ${ }^{[13]}$ The addition of sodium thiosulfate, which can reduce iodine to iodide, turned the solution colourless, which further supports the identification of the product as iodine.

To further analyze the compositional change in the aged films SEM-EDX measurements were performed. EDX analysis showed the $\mathrm{Pb}$ :I ratio to deplete from 1:3 to 1:2 in the fresh and degraded samples respectively, as illustrated in Figure $\mathbf{3 b}$. 
An X-ray diffraction analysis of the samples (Figure 4) reveals the characteristic peaks of methylammonium lead iodide in the fresh sample. ${ }^{[14,15]}$ These peaks are largely diminished in the degraded sample and distinct additional peaks stemming from $\mathrm{PbI}_{2}$ are detected. The formation of $\mathrm{PbI}_{2}$ was additionally confirmed by Raman spectroscopy, which clearly shows the characteristic peaks of $\mathrm{PbI}_{2}$ that coincide with a $\mathrm{PbI}_{2}$ reference sample (see supporting information, Figure S2).

Having identified two of the degradation products, the next question that arises relates to how the superoxide species causes degradation of the perovskite. One possibility is that the superoxide reacts with the organic component of the perovskite (i.e. methylammonium cation). To test this hypothesis and to better understand the degradation mechanism we investigated whether the methylammonium cations are undergoing any transformation. For this purpose, a model reaction was set up and NMR spectroscopy was employed to monitor the transformation. The model reaction consisted of a sample of MAI dissolved in dry ethanol, to which potassium superoxide was added $\left(\mathrm{KO}_{2}\right)$. The sample was then transferred to an NMR tube to which some deuterated acetone was added for calibration of the spectrum. The reaction proceeded with a colour change, from colourless to orange. Proton NMR spectra of the sample and of a control containing only methylammonium iodide are shown in Figure 5. Both the signal for the $\mathrm{NH}_{3}{ }^{+}$and the methyl group protons shift up-field upon addition of potassium superoxide, which is consistent with the deprotonation of the ammonium group to form methylamine. The presence of iodine in the sample was again determined by the addition of sodium thiosulfate, which turned the solution from orange to colourless. The $\mathrm{pH}$ of the solution was also estimated with $\mathrm{pH}-\mathrm{paper}$ to be around 10 . This could be accounted for by the potential formation of $\mathrm{KOH}$ due to the potassium 
salt being used in the model reaction. It is therefore plausible that water can be formed in the oxygen and light assisted degradation of $\mathrm{CH}_{3} \mathrm{NH}_{3} \mathrm{PbI}_{3}$.

Herein we have shown that the degradation of the mp- $\mathrm{Al}_{2} \mathrm{O}_{3} / \mathrm{CH}_{3} \mathrm{NH}_{3} \mathrm{PbI}_{3}$ sample in a moisture free environment can be accounted for by the generation of superoxide through electron transfer from the photoexcited perovskite phase to molecular oxygen. The present findings suggest that the superoxide acts to break down the perovskite by first deprotonating the methylammonium cation as shown by NMR spectroscopy. Moreover, the deprotonation of the methylammonium cation ultimately leads to the formation of $\mathrm{PbI}_{2}$, as confirmed by XRD and Raman spectroscopy, and iodine, detected by UV-Vis spectroscopy and confirmed by addition of sodium thiosulphate. Based on these observations we propose a possible reaction scheme for the degradation (see Figure 6). It is pertinent that water is expected to be another by-product of decomposition as discussed above. The resulting water could then participate in further degradation pathways, perhaps similar to the ones reported in the literature, where the water would now act as the active species in the degradation or act to hydrate the perovskite. ${ }^{[8,9]}$ The overall effect after a first action of superoxide on the perovskite will be an increase on the decomposition rate, since, even if the $\mathrm{CH}_{3} \mathrm{NH}_{3} \mathrm{PbI}_{3}$ is carefully encapsulated in a water-free environment, degradation can be triggered by the presence of oxygen and light. It is therefore crucial to ensure that $\mathrm{CH}_{3} \mathrm{NH}_{3} \mathrm{PbI}_{3}$ perovskite layers, when incorporated in photovoltaic devices, are isolated from both water and oxygen. Additionally, the implementation of a mesoporous electron-extracting layer (e.g. mp$\mathrm{TiO}_{2}$ ) can facilitate the deactivation of the electron transfer process to oxygen, resulting in reduced superoxide generation. Obtaining more efficient electron extraction should lead to enhanced stability in moisture-free environments. Alternatively material design 
aimed at replacing the methylammonium cation to a species without acid protons could improve stability and may alleviate the need for oxygen barriers.

\section{Experimental Methods}

Materials: All chemicals were purchased from Sigma-Aldrich and used as received, except $\mathrm{TiO}_{2}$ nanoparticles from Dyesol and methylammonium iodide, which was synthesized in the lab.

Synthesis of methylammonium iodide: Methylamine solution (33 wt. \%) in ethanol (6.2 $\mathrm{mL}, 0.046 \mathrm{~mol}$ ) was cooled down in an ice bath. Hydroiodic acid solution (55 wt. \%) in water $(10 \mathrm{~mL}, 0.073 \mathrm{~mol})$ was then added dropwise under vigorous stirring. The reaction was stirred for $1 \mathrm{~h}$ at $0{ }^{\circ} \mathrm{C}$. The product crashed out from the solution as a white-yellowish solid. Ethanol $(5 \mathrm{~mL})$ was added to ensure full precipitation of the solid, which was filtered and washed with cold ethanol. Recrystallization of the product in chloroform afforded the pure compound as white crystalline solid (6.4 g, $87 \%)$.

Film Fabrication: All films were deposited onto clean glass substrates, of ca. $1 \mathrm{~cm}$ by $1 \mathrm{~cm}$ size. The glass substrates were washed sequentially in acetone, deionized water and isopropylalcohol (IPA) under sonication for 10 minutes during each washing cycle. A Laurell Technologies WS-650MZ-23NPP Spin Coater was used to fabricate the films. A $1 \mathrm{M}$ solution of $\mathrm{CH}_{3} \mathrm{NH}_{3} \mathrm{PbI}_{3}$ was formed by adding $\mathrm{PbI}_{2}$ in a 1:1 molar ratio with methylammonium iodide in a solvent mixture of 4:1 gamma-butyrolactone (GBL) to DMSO. This solution was then spin-coated onto the substrates using a consecutive 
two-step spin program under a nitrogen atmosphere in a glovebox. The first spinning cycle is performed at $1000 \mathrm{rpm}$ for $10 \mathrm{~s}$ followed by $5000 \mathrm{rpm}$ for $20 \mathrm{~s}$, as reported by Jeon et al. ${ }^{[16]}$ During the second phase, the substrate was treated with toluene ( 350 $\mathrm{mL})$ drop-casting. The films were then annealed at $100{ }^{\circ} \mathrm{C}$ for 10 minutes. The perovskite layers were deposited onto mesoporous $\mathrm{Al}_{2} \mathrm{O}_{3}$ and mesoporous $\mathrm{TiO}_{2}$ films prepared as follows:

a) Mesoporous $\mathrm{Al}_{2} \mathrm{O}_{3}$ layers were fabricated on cleaned glass substrates by spin coating (4500 rpm for $45 \mathrm{~s}$ ) an $\mathrm{Al}_{2} \mathrm{O}_{3}$ dispersion prepared in a 2:1 vol. ratio of $\mathrm{Al}_{2} \mathrm{O}_{3}(<50 \mathrm{~nm}$ particle size in IPA solution) and IPA. After spin coating, the films were placed on a hotplate at $150{ }^{\circ} \mathrm{C}$ for 30 minutes.

b) Mesoporous $\mathrm{TiO}_{2}$ based films were fabricated using a paste of $20 \mathrm{~nm} \mathrm{TiO}_{2}$ nanoparticles in a 1:5 weight ratio with dry ethanol. This was spin-coated onto glass substrates at $6000 \mathrm{rpm}$ for $30 \mathrm{~s}$. Once spun, the films were sintered at $450{ }^{\circ} \mathrm{C}$ for 1 hour in a furnace.

Probe Testing: A stock solution $(31.7 \mu \mathrm{M})$ of the hydroethidine (HE) probe was prepared by dissolving $10 \mathrm{mg} \mathrm{HE}$ in $10 \mathrm{~mL}$ of dry toluene; sonication was used to facilitate miscibility. Films were then added to $10 \mathrm{~mL}$ of $0.317 \mu \mathrm{M}$ solution created from the stock solution. Photoluminescence spectra were recorded using an excitation wavelength of $520 \mathrm{~nm}$ and a slit width of $10 \mathrm{~mm}$ on a Horiba Yobin-Ybon Fluorolog3 spectrofluorometer. In the experiments with oxygen involved, dry oxygen was gassed through the toluene. For the control using $\mathrm{N}_{2}$, a Schlenk line was used to continuously flow nitrogen through the system. 
Ageing Conditions: Films were submerged in $10 \mathrm{~mL}$ dry toluene. Toluene (99.8\%) was dried over molecular sieves, with a pore size of ca. $3 \AA$ A. Dry air was gassed through for the duration of the degradation. Illumination was provided by a tungsten lamp of approximately $1.5 \mathrm{mWcm}^{-1}$ power.

Superoxide Model Reaction: Potassium superoxide and methylammonium iodide were dissolved in a 1:1 molar ratio in dry ethanol. The reaction resulted in a colour change from colourless to orange.

Characterization: ${ }^{1} \mathrm{H}$ NMR spectra were recorded on a $400 \mathrm{MHz}$ Bruker spectrometer using TopSpin software. UV-Vis spectra were acquired on a PerkinElmer UV/VIS Spectrometer Lambda 25. X-ray diffraction patterns were measured on a PANalytical X'Pert Pro MRD diffractometer using Ni filtered $\mathrm{Cu} \mathrm{K}_{\alpha}$ radiation at $40 \mathrm{kV}$ and $40 \mathrm{~mA}$. SEM-EDX measurements were carried out on a JEOL 6400 scanning electron microscope operated at $20 \mathrm{kV}$. 


\section{References}

[1] J. Burschka, N. Pellet, S.-J. Moon, R. Humphry-Baker, P. Gao, M. K.

Nazeeruddin, M. Graetzel, Nature, 2013, 499, 316-319.

[2] D. Bi, S.-J. Moon, L. Haggman, G. Boschloo, L. Yang, E. M. J. Johansson, M. K.

Nazeeruddin, M. Graetzel, A. Hagfeldt, RSC Adv. 2013, 3, 18762-18766.

[3] M. M. Lee, J. Teuscher, T. Miyasaka, T. N. Murakami, H. J. Snaith, Science 2012, $338,643-647$.

[4] O. Malinkiewicz, A. Yella, Y. H. Lee, G. Minguez Espallargas, M. Graetzel, M.

K. Nazeeruddin, H. J. Bolink, Nat. Photonics 2014, 8, 128-132.

[5] T. Leijtens, G. E. Eperon, S. Pathak, A. Abate, M. M. Lee, H. J. Snaith, Nat. Commun. 2013, 4, 2885.

[6] H. P. Zhou, Q. Chen, G. Li, S. Luo, T. B. Song, H. S. Duan, Z. R. Hong, J. B. You, Y. S. Liu, Y. Yang, Science 2014, 345, 542-546.

[7] J. A. Christians, P. A. Miranda Herrera, P. V. Kamat, J. Am. Chem. Soc. 2015, $137,1530-1538$.

[8] G. Niu, W. Li, F. Meng, L.Wang, H. Dong, Y. Qiu, J. Mater. Chem. A 2014, 2, 705-710.

[9] J. Yang, B. D. Siempelkamp, D. Liu, T. L. Kelly, ACS Nano 2015, DOI:10.1021/nn506864k

[10] F. T. F. O’Mahony, Y. H. Lee, C. Jellett, S. Dmitrov, D. T. Bryant, J. R.

Durrant, B. C. O’Regan, M.Graetzel, M. K. Nazeeruddin, S. A. Haque, J. Mater. Chem. A, 2015, 3, 7219-7223

[11] A. Gomes, E. Fernandes, J. Lima, J. Biochem. Biophys. Methods 2005, 65, 4580. 
[12] H. J. Snaith, J. Phys. Chem. Lett. 2013, 4, 3623-3630.

[13] O. J. Walker, Trans. Faraday. Soc. 1935, 31, 1432-1438.

[14] T. Baikie, Y. Fang, J. M. Kadro, M. Schreyer, F. Wei, S. G. Mhaisalkar, M.

Graetzel, T. J. White, J. Mater. Chem. A 2013, 1, 5628-5641.

[15] D. S. Bhachu, D. O. Scanlon, E. J. Saban, H. Bronstein, I. P. Parkin, C. J.

Carmalt, R. G. Palgrave, J. Mater. Chem. A 2015, DOI: 10.1039/C4TA05522E

[16] N. J. Jeon, J. H. Noh, Y. C. Kim, W. S. Yang, S. Ryul, S. I. Seok,. Nat. Mater. 2014, 13, 897-903.

\section{Acknowledgments}

S.A.H. acknowledges financial support from the Engineering and Physical Sciences Research Council (EPSRC) through EP/H040218/2 and EP/K010298/1 projects. S.A.H. acknowledges financial support from the European Community's Seventh Framework Programme (Nanomatcell, grant agreement number 308997). T.R. acknowledges financial support from the Austrian Science Fund (FWF) under the grant number J3515-N20. 


\section{Figures}

(a)

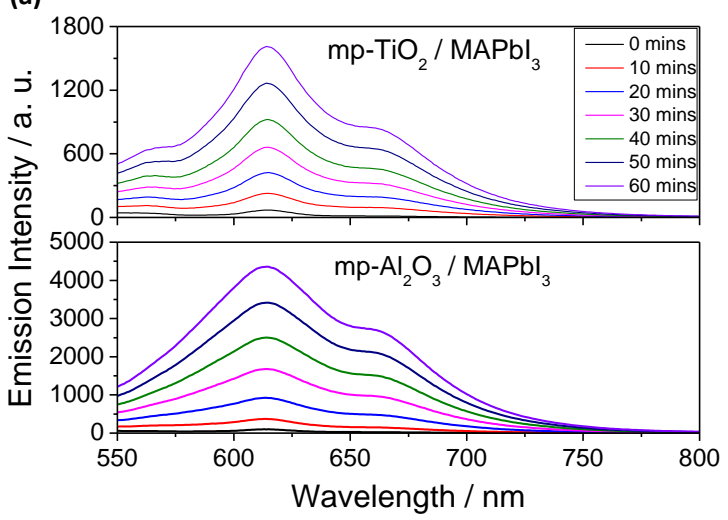

(b)

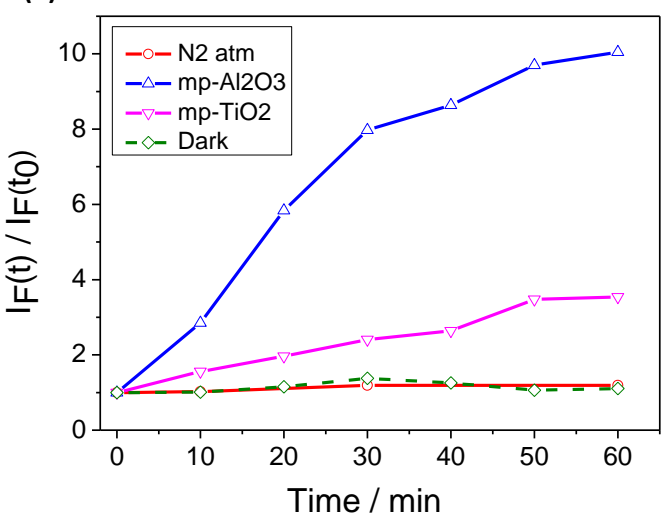

Figure 1. a) Raw emission data collected from the probe solution, highlighting the increasing intensity observed with ageing under illumination and dry air flux. b) Normalised fluorescence intensity at $610 \mathrm{~nm}$ of the superoxide probe solution, with excitation at $520 \mathrm{~nm} . \mathrm{I}_{\mathrm{F}}(\mathrm{t})$ is the fluorescence intensity maximum at time $\mathrm{t}$, whilst $\mathrm{I}_{\mathrm{F}}\left(\mathrm{t}_{0}\right)$ is the background fluorescence intensity of the probe. 


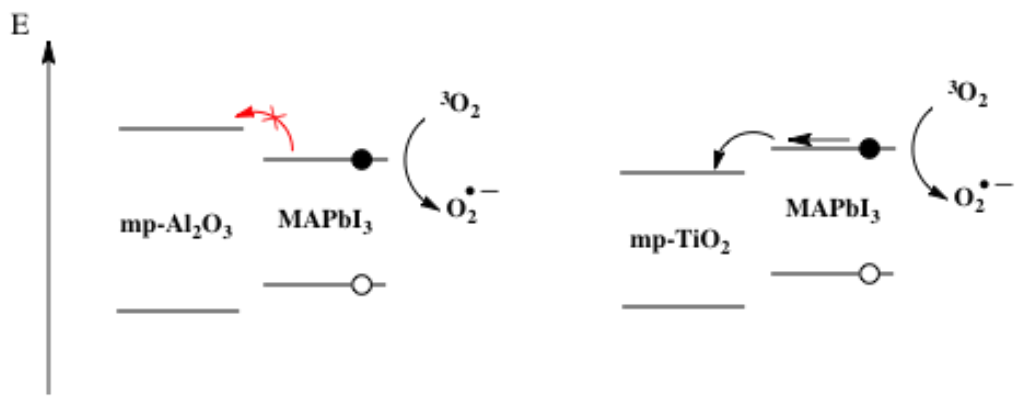

Figure 2. Schematic model showing the electron transfer of the photo-excited electrons in the MAPI layers to oxygen resulting in the formation of superoxide. Depending on the mesoporous metal oxide, a competing electron transfer process can occur, resulting in the reduced superoxide production. 
(a)

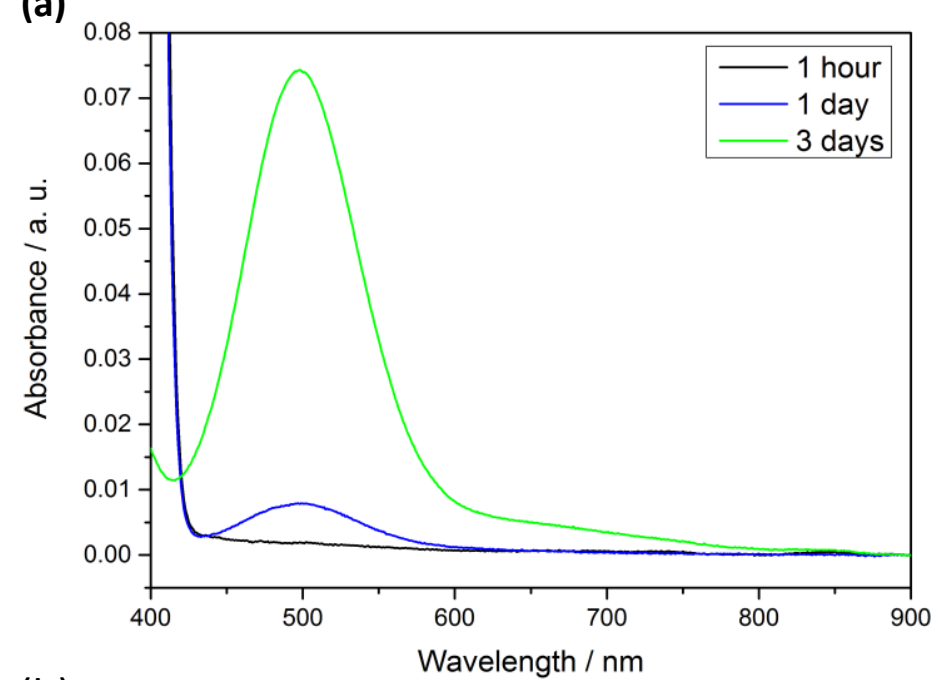

(b)
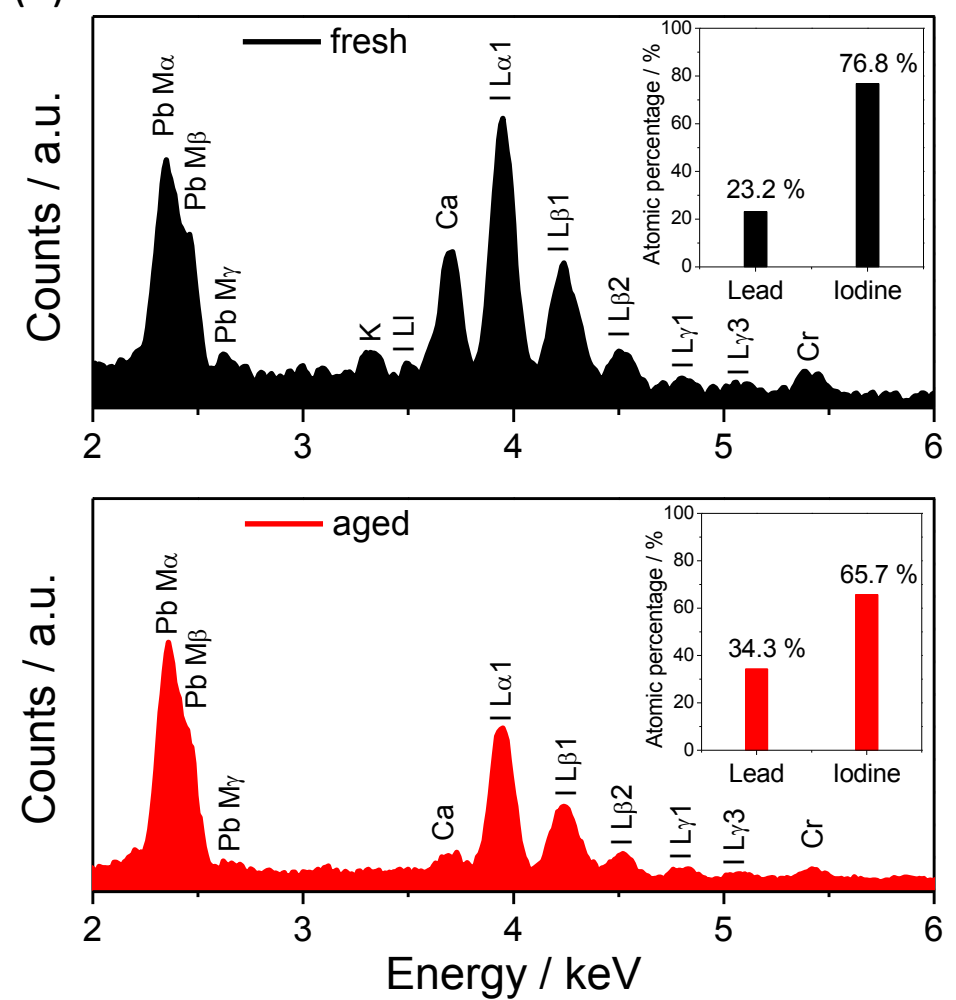

Figure 3. a) UV-Vis spectra showing the production of iodine over a 72-hour time period, during which the mp- $\mathrm{Al}_{2} \mathrm{O}_{3} / \mathrm{MAPI}$ films were continuously subjected to the degradation conditions. b) SEM-EDX spectra and elemental composition analysis showing that on ageing the molar ratio of $\mathrm{Pb}: \mathrm{I}$ in the sample changes from 1:3 to 1:2. Peaks in the spectra not assigned to $\mathrm{Pb}$ or I stem from the glass substrate or the chromium coating of the samples to prevent charging during the SEM-EDX analysis. 


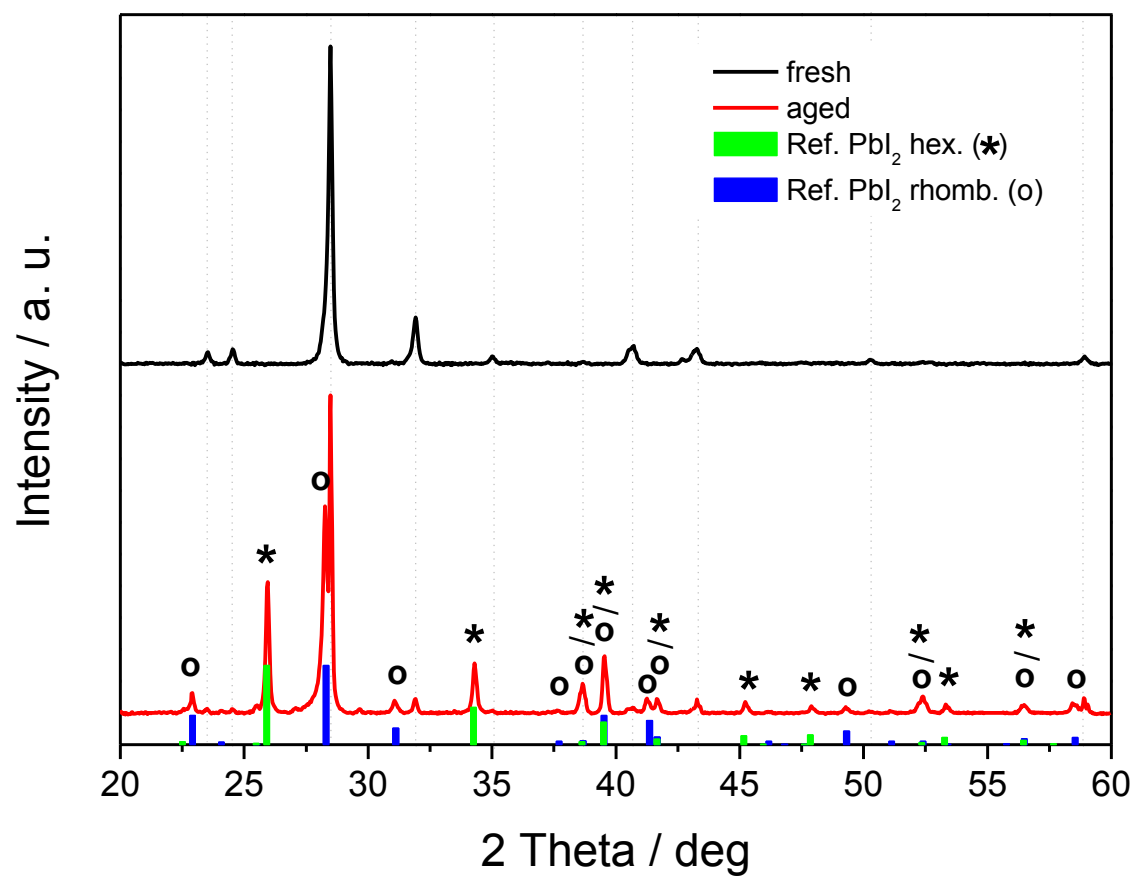

Figure 4. X-ray diffraction patterns of a fresh and an aged sample revealing the formation of $\mathrm{PbI}_{2}$ as the result of degradation in a moisture free environment. Dotted vertical lines in the graph indicate the peak positions of methylammonium lead iodide according to literature data. ${ }^{[14,15]}$ The additional peaks in the degraded sample can be assigned to $\mathrm{PbI}_{2}$ (reference patterns: PDF 01-080-1000 for hexagonal and PDF 01-0731753 for rhombohedral $\mathrm{PbI}_{2}$ ). 


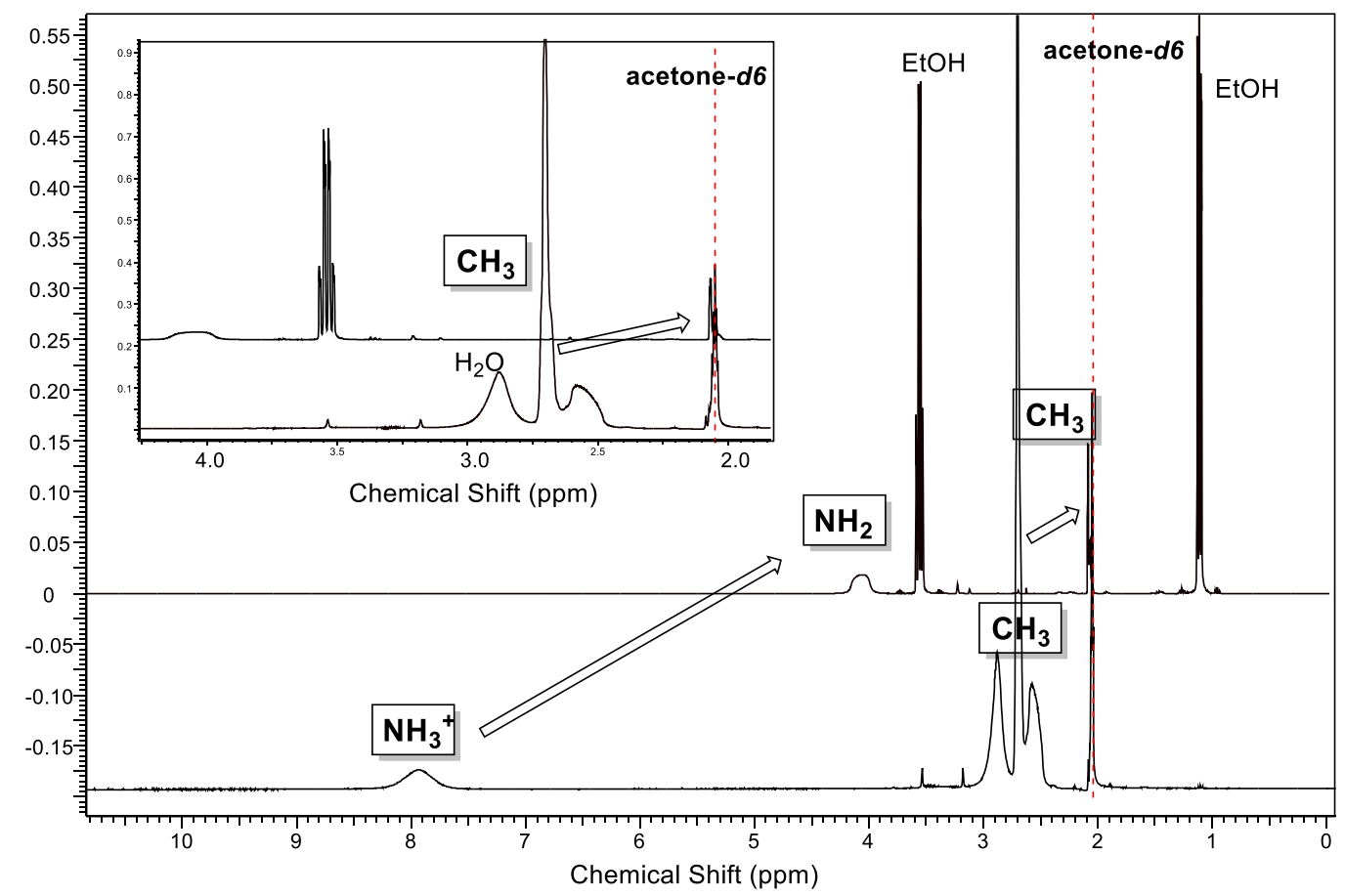

Figure 5. NMR spectra of a reference sample containing methylammonium iodide (bottom) and the resulting spectra after addition of potassium superoxide. Inset shows an expansion of the methyl signal. 


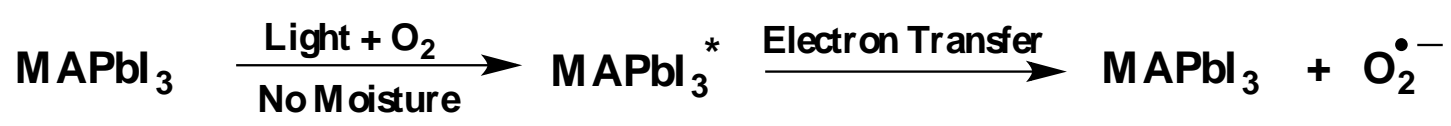

$\mathrm{MAPbl}_{3}+\mathrm{O}_{2}^{\cdot-} \stackrel{\text { Deprotonation }}{\longrightarrow} \mathrm{MeNH}_{2}+\mathrm{Pbl}_{2}+\mathrm{I}_{2}+\mathrm{H}_{2} \mathrm{O}$

Figure 6. Reaction scheme indicating a potential route for degradation caused by superoxide as predicted from the obtained data reported. The $\mathrm{MAPbI}_{3} *$ intermediate indicates photo-excitation and the formation of the photo-generated electron that is subsequently transferred to oxygen. 